\title{
An Online Learning Platform for College Students
}

\author{
Gui-zhen WANG \\ Network Information Center \\ Qilu University of Technology \\ Jinan, China \\ wgz@qlu.edu.cn
}

\begin{abstract}
With the rapid development of new technologies, the traditional methods of teaching are losing their appeal for college students. In order to improve the teaching quality and learning effect, many other teaching and learning methods have been extended on the basis of the traditional teaching, and the online learning which is mainly based on college students is the most prominent. People's more and more attention are focused on the online learning platform acting as a secondary teaching module. In the online learning platform described in here, the Asp.Net is used as the main development tool and the SQL Server database is used as the acquired storage. The "online learning" and "online evaluation" are the two main function modules of the online learning platform system run on the Windows system. The "online learning" is students choose their favorite courses to learn which are edited and inputted into the online learning platform system firstly by teachers. The "Online evaluation" is students taking the examination which are generated by teachers with random questions. Through each student's record of online to participate in the course training, test exercises, online communication, etc., the students' tracking management of the learning whole process can be achieved. Through more than a year of experimental tests, the online platform users reached more than ten thousand people, and received good feedback results. As much more course can be added into the online learning platform to provide learners with a wealth of learning resources, it has a certain reference value.
\end{abstract}

Keywords—education; teaching; online learning; web

\section{INTRODUCTION}

With the rapid development of society and technology, the traditional teaching mode has been unable to meet the needs of modern education. The network environment platform methods is used to meet their own needs of learning and education which is advanced and popular. The online learning platform was studied in many universities in the United States since the popularity of the network [1]. It was thought that the online education was not inferior to face to face education in a large proportion of the academic field. Today, the network can be seen everywhere in society because all aspects of social life are gradually affected by the network. The teaching change of the traditional is inevitable, and it is an inevitable trend by online learning .The learning tests can be done at any time and place learning through a wide range of Internet. The flexibility of learning is greatly expanded, and many troublesome restrictions are freed [2].
At present, Web-based online learning platform is increasingly popular with users, it eliminates the trouble of installing the client software, and users can participate in online learning as long as a computer connected to the Internet without time and location restrictions. The more detailed description is introduced in the literature [3]. And the literature $[4,5]$ points out that it can not only use the computer's huge computing power and storage capacity, building a huge knowledge base, but also can be carried out in different places of the world because it is based on the Web development platform [6]. There is a strong convenience and flexibility for it can be applied on an internal network, or it can be applied across the Internet.

Here an online learning platform is introduced, and the main content is organized as follows:

(1)An online learning platform for college students using Web technology is introduced after the enumeration of problems in traditional classroom teaching in the introduction section.

(2)The technology used in the platform development is described.

(3)The system design, indicating the main components of the entire system and some E-R diagram of important data entities.

(4)The summary of the text is given, including the achievements and the deficiency.

\section{SYSTEM DEVELOPMENT PLATFORM}

For the $\mathrm{B} / \mathrm{S}$ model, it is the browser and server structure. Users access the online exam system and perform related operations through the browser way. In this way, few part of the work is done at the front end, but most of the other work is done on the back-end Web server. Through this method, system consumption and maintenance costs are significantly reduced. The specific $\mathrm{B} / \mathrm{S}$ structure is described in detail in the literature [4].

SQL Server is a database management system launched by Microsoft. It can help store relational and structured data, providing us with the possibility of a secure management business. ASP.NET Development Server provides web pages for requests from browsers on the local computer, does not provide web pages for other computers, and does not provide 
application-wide files. It can now be a local test before the IIS server is released, which is an effective way to test the web.

As described in [6], AJAX is now widely used to create an interactive web application web development technology AJAX browser and Web server to communicate asynchronously between, and at the same time to send and receive XML. This allows the Web application to respond more quickly to the user's actions and avoid sending data that has not changed. It optimizes the transfer between the browser and the server, reduces the probability of unnecessary data round-trip, and reduces the bandwidth consumption. Because the client is running, the server takes part of the work and reduces the load on the server.

\section{DESIGN OF SYSTEM}

\section{A. Overall design}

According the user roles, the online learning platform is divided into students, teachers and administrators. However, according to the function of modules, the online learning platform includes the courses management module, the questions bank management module, the exercises and test management, and the personal information management module. The overall function modules of the online platform is shown in Fig 1.

In the course module includes teachers course management, students selecting course, and administrator management. Teachers question bank management, students select question bank and administrator management are composed the question bank module. Teachers test paper management, teachers tests management and students online examination are included in the examination module. In the information management module, there are three components such as teachers' information management, students' information management and administrators' information management.

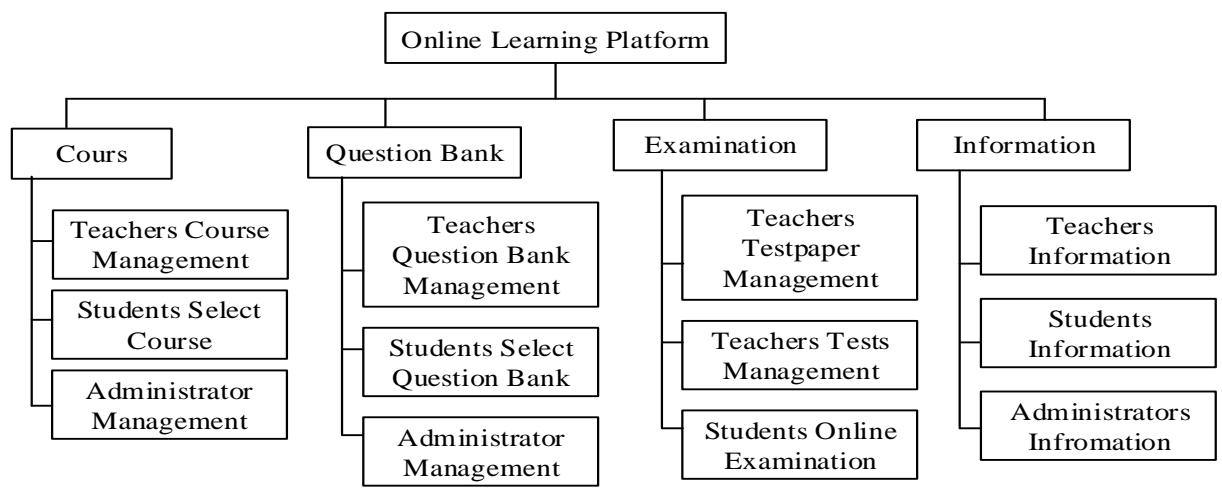

Fig. 1 System Components

\section{B. Database design}

As a system that requires a lot of data processing and data storage, the establishment of a database of online learning platforms is very important.

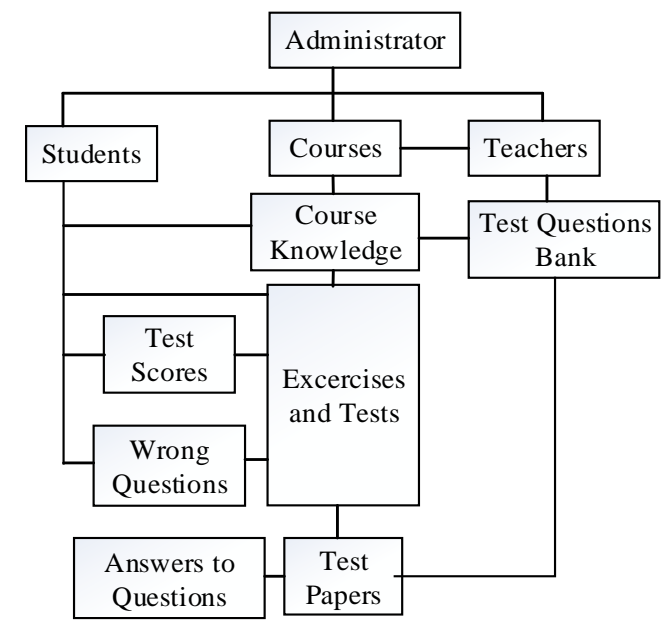

However, before establishing the database, in order to ensure the correctness of the design and improve efficiency, the relationship between data entities need to be studied by using the E-R diagram. The online learning platform includes administrators, teachers, students, course bank, test questions bank, exercises and tests, papers, test scores, answers to papers, wrong questions and other entities. As shown in Fig. 2 there are complex relationships, which can be achieved through the foreign keys of the database tables, between the various entities.

For example, a test paper contains multiple questions, however, a question can appear in multiple papers. In addition, each entity has its own attributes, such as a student entity with student identify, true name, professional class, login-password, contact and other attributes. Limited to space, here only a few key entities are introduced in the following sections.

\section{1) Students Entity}

The students entity shown in the Fig. 3 contains student account number, true name, password, gender, students' ID number, telephone, payment, photo and other attributes.

Fig. 2 Data Entities of the system 


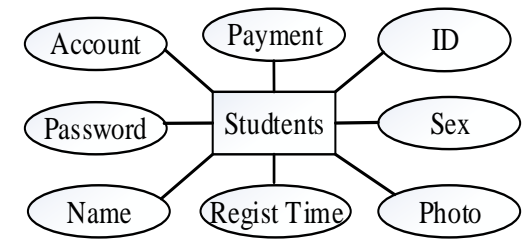

Fig. 3 Students Entity

\section{2) Course Entity}

The courses entity shown in the Fig. 4 is used to record course information, including course ID, course name, course introduction, teaching content, study fees, visits, teachers, number of students enrolled, learning costs etc.

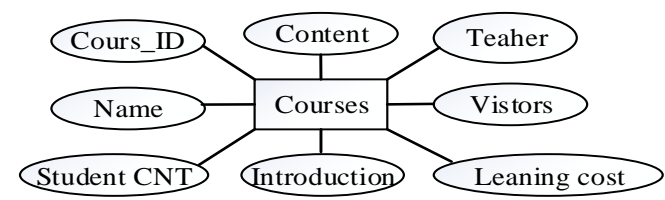

Fig. 4 Courses Entity

\section{3) Questions Entity}

The questions entity shown in the Fig. 5 is used to record question information, including question ID, question type, title, answer, score, subject of the question, degree of difficulty etc. The question type includes single choice, multiple choice, judgment, filling in the bank and short-answer. The question ID is the foreign key associate with other entities.

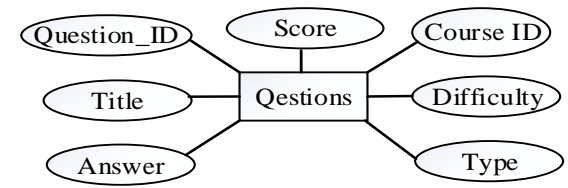

Fig. 5 Questions Entity

In relational database, table is a kind of important components. All data in a relational database is managed in the form of a table which is the basic object for it is always used to store data and operate data. Creating table is the base operation of database.

In the database of online learning system, there are thirteen tables such as students' information table(t_StudentsInfor), students' classification table(t_StudentKind), students' error exercises table(t_StuErrExerItem), teacher's information table(t_TeachersInfor), teachers' resume (t_TeacherResum), subject table (t_Subject), curriculum table(t_Course), test question-bank table(t_QuestionBank), question answers table(t_QuestionAnser), test table(t_TestPaper), examination table (t_Examination), test sub item table(t_TestPagerItem) and test scores table(t_TestScore). Due to limited space, only a few key tables are presented in the followings:

\section{4) t_StudentsInfor}

Students' information table named t_StudentsInfor includes student account number, name, password, gender, ID number, telephone, photo and other attributes. Among them, the student account St_AccName is set as the primary key. It can only identify the constraints to ensure that each data content will not be exactly the same. Some important fields of $t \_$StudentsInfor are shown in the following Table I.

TABLE I. t_sudentsInfor

\begin{tabular}{|c|c|c|c|}
\hline Fields & DataType & Description & Key \\
\hline St_AccName & nvarchar & $\begin{array}{l}\text { Student account } \\
\text { number }\end{array}$ & Yes \\
\hline St_Pwd & nvarchar & password & No \\
\hline St_Name & nvarchar & actual name & No \\
\hline $\begin{array}{l}\text { St_IDCardNu } \\
\mathrm{m}\end{array}$ & nvarchar & ID number & No \\
\hline St_Photo & nvarchar & photo & No \\
\hline St_Phone & nvarchar & phone & No \\
\hline St_Reg Time & datetime & Registration time & No \\
\hline St_Last Time & datetime & last login time & No \\
\hline Sts_CID & int & $\begin{array}{l}\text { Student classification } \\
\text { ID }\end{array}$ & No \\
\hline Sts_Name & nvarchar & $\begin{array}{l}\text { Name of student } \\
\text { classification }\end{array}$ & No \\
\hline
\end{tabular}

\section{5) t_StuErrExerItem}

Students' error exercises table named t_StuErrExerItem is a summary of their failing when they do exercises or exams. The t_StuErrExerItem table can help students to review, strengthen memory and improve themselves. As shown in the Table II, there are some feilds such as Squs_ID, st_ID, Qus_ID and so on are described in the Table II.

TABLE II. t_StuErrExerItem

\begin{tabular}{|c|c|c|c|}
\hline Fields & Data Type & Description & Key \\
\hline Squs_ID & int & Self-incrementing key ID & Yes \\
\hline St_ID & int & Student ID & No \\
\hline Qus_ID & int & Questions ID & No \\
\hline Qus_Diff & int & $\begin{array}{l}\text { The difficulty level of the } \\
\text { questions }\end{array}$ & No \\
\hline Sbj_ID & int & $\begin{array}{l}\text { The classification of the } \\
\text { questions }\end{array}$ & No \\
\hline Qus_Typ & int & Classification of questions & No \\
\hline Squs_ID & int & Self-incrementing key ID & No \\
\hline St_ID & int & Student ID & No \\
\hline Qus_ID & int & Questions ID & No \\
\hline Qus_Diff & int & $\begin{array}{l}\text { The difficulty level of the } \\
\text { questions }\end{array}$ & No \\
\hline
\end{tabular}

\section{SUMMARY}

An online learning platform for college students using Web technology is introduced. The online learning platform based on Web can also enhance the learning effect, which is different from the traditional teaching. The way of learning is changing gradually from the "forced to learn" to "autonomy". Although the on line learning system has obtained certain fruits in the actual teaching process, there are many aspects need to be improved for the urgent time and the author's ability. 


\section{REFERENCES}

[1] Olivier Loquineau Aur, élien Caplan, and Karine Toumazeau, On the Intention to Use an Online Learning Platform Feature. Scientific Journal of Riga Technical University, Computer Sciences, 2011, Vol.43 (1), pp.92-98 De Gruyter.

[2] Z. J. Wang, X.F. Xu, and D. C. Zhan, Inter-enterprise Integration Oriented Normalized Design Method for Web Services, Computer Science, vol.33, pp. 131-135, 2006.

[3] Pawe Lenkiewicz, Lech Banachowski, and Jerzy Pawe Nowacki, Advances in Intelligent Information and Database Systems, Studies in Computational Intelligence, 2010 Springer.
[4] Zhou Guo Bing, Liu Ting Ting, and Liu Xinxin, Algorithm and strategyresearch of generating test paper for large scale online examination, Electronic and Mechanical Engineering and Information Technology (EMEIT), pp.3285-3288, 2011.

[5] Paulson, Linda Dailey, Building Rich Web Applications with Ajax, Industry Trends Computer, vol.10, pp.14-17, 2014.

[6] Zhang D, Wei Z, and Yang Y. Research on Lightweight MVC Framework Based on Spring MVC and Mybatis, Sixth International Symposium on Computational Intelligence and Design, pp.350-353, 2013 